Saudi Journal of Oral and Dental Research

Abbreviated Key Title: Saudi J Oral Dent Res

ISSN 2518-1300 (Print)|ISSN 2518-1297(Online)

Scholars Middle East Publishers, Dubai, United Arab Emirates

Journal homepage:https://saudijournals.com/sjodr

\title{
Evaluation of Mandibular Incisive Canal with Mental Foramen: A Retrospective Study Using CBCT
}

\author{
Ayesha Roul $^{1 *}$, Jaideep Sur, MDS ${ }^{2}$, Fatima Khan, MDS $^{3}$, Deeplaxmi Dewangan, MDS $^{4}$, Sourav Bose ${ }^{5}$, Ekta Sawriya ${ }^{6}$ \\ ${ }^{1}$ Post Graduate, Oral Medicine and Radiology, Rungta College of Dental Sciences and Research, Bhilai, Chhattisgarh, 490024, India \\ ${ }^{2}$ Oral Medicine and Radiology, Professor and Head of the Department, Rungta College of Dental Sciences and Research, Bhilai, Chhattisgarh, 490024, \\ India \\ ${ }^{3}$ Oral Medicine and Radiology, Reader, Rungta College of Dental Sciences and Research, Bhilai, Chhattisgarh, 490024, India \\ ${ }^{4}$ Oral Medicine and Radiology, Reader, Rungta College of Dental Sciences and Research, Bhilai, Chhattisgarh, 490024, India \\ ${ }^{5}$ Post graduate, Oral Medicine and Radiology, Rungta College of Dental Sciences and Research, Bhilai, Chhattisgarh, 490024, India \\ ${ }^{6}$ Post graduate, Oral Medicine and Radiology, Rungta College of Dental Sciences and Research, Bhilai, Chhattisgarh, 490024, India
}

DOI: $10.36348 /$ sjodr.2020.v05i09.006

| Received: 22.08.2020| Accepted: 30.08.2020| Published: 03.09.2020

*Corresponding author: Dr. Ayesha Roul

Abstract

Aim and objective: To evaluate the presence, width and the initial part of mandibular incisive canal (MIC) and its relationship with the mental foramen (MF) in 60 CBCT scans for pre-surgical implant planning. Material and methods: In this retrospective analysis, random samples of 60 mandibular CBCT scans were taken to examine the dimension of MIC and its relationship to MF. Result: The location and measurements of the MIC in a contiguous system is measured by 60 CBCT scans. MIC was identified in 71.67 percent of cases with a mean diameter of $2.56 \mathrm{~mm}$, i.e. $45 \%$ started before MF and $26 \%$ began extremely close to foramen. Conclusion: The results from this analysis indicates that the presurgical preparation of the MIC in CBCT should be performed in order to ensure a minimally invasive and optimum location of the implant.

Keywords: Mental Foramen, Cone-Beam Computed Tomography, Radiography.

Copyright @ 2020: This is an open-access article distributed under the terms of the Creative Commons Attribution license which permits unrestricted use, distribution, and reproduction in any medium for non-commercial use (Non Commercial, or CC-BY-NC) provided the original author and source are credited.

\section{INTRODUCTION}

Technological amelioration in recent years has meant that surgery in the anterior segment of the mandible, including orthognathic surgery, dental implant placement, bone graft and lowering of the genial spine, has become more frequent in edentulous patients[1,2]. In the literature, complications can be found due to anatomical variation in the lower alveolar nerve, as this nerve may split to the incisive nerve canal, extending earlier to the mental foramen (MF) towards the midline[3]. The mandibular incisive neurovascular bundle is rarely a matter of concern to implants of the lower anterior jaw [4]. Most common accidental complications such as neurosensory disturbances can happen during the surgery, if not identified properly. If an anterior loop to the mental nerve is not present, the mandibular region of the MF is usually regarded as a healthy operative area during implant osteotomy [5]. Several case reports describe the neurosensory disruption, edema, hemorrhage and failure of osseointegration of implants during or after surgical procedures within the interforaminal region of the mandible [6]. Osteotomies frequently enter the mandibular incisive canal (MIC) without substantial danger of disruption in the vital anatomical structures [7]. A radiographic analysis of potential surgical sites is among the most important elements of pre-operative evaluation. However, the ability to interpret the incisive canal from conventional radiographs remains limited [1, 8] with the increased interest in performing a thorough presurgical examination in the inter-foraminal region, cross-sectional images can be obtained from cone-beam computed tomography (CBCT) and are utilized to collect data on the position, location and course of foramina and canal and their relationship with the other anatomic structures of the jaw. CBCT in the dental practice allows visualizing small bone structures with high spatial resolution and a low dose [9]. Based on the understanding that having a clear picture of surgical site improves the safety of operating procedures, this research will determine the location, the width and initial portion of MIC and its relationship with the MF, in 60 CBCT scans. 
Roul A et al., Saudi J Oral Dent Res, September, 2020; 5(9): 447-451

\section{MATERIAL AND METHODOLOGY}

In 60 randomized CBCT scans, the retrospective analysis was carried out in Chhattisgarh at the Siddh-Ora View centre. The scans were of the entire mandible from the anterior two-third of the ramus on the right side to the left side, with the presence of one or more teeth, bilaterally in the mental foramen region. All the CBCT scans were performed using SIRONA ORTHOPHOS XG 3D (85KV, 14.4s, 6mA, 8*5 FOV). MICs were identified and measured using SIDEXIS software using GALAXIS GALILEOS Viewer. A single observer viewed in the images using a Dell laptop (Intel Core i3 processor, $1.90 \mathrm{GHz}, 4 \mathrm{~GB}$ RAM, Intel HD Graphics: 15.6 HD LED LCD monitor, Windows 10 operating system). The data collected was entered in the Microsoft office Excel spreadsheet which was then transferred to Statistical Package for the Social Sciences (SPSS) version 16 for statistical analysis.The incident of MIC occurred bilaterally on the mental foramen in the axial view of the images in each scan and then panoramic images were tracked by the nerve tracking tool. Transversal pictures have also been analyzed to validate them. The panoramic view of CBCT was used to identify the MIC and its original portion. The initiation of the MIC in relation to the MF was evaluated and classified as:[9]Type 1.MIC starting before the opening of MF. (Figure 1A) Type 2.MIC at the level of MF. (Figure 1B)Bilateral assessment of the spatial relationship of the adjacent MIC sagittal structures was taken of each tooth preceding mental foramen. Based on this, five measurements were obtained i.e. $[4,6]$ the inner side of the MIC to the labial buccal and the lingual buccal plate (Figure 2A and 2B), the diameter of the MIC (Figure 2C), and upper cortical boundary of the mandible (Figure 2D and 2E).

\section{RESULT}

CBCT scans of 60 patients were studied and an analysis of the results showed that 43 scans had been for the MIC (71.67\%). (Table 1)Out of 43 scans Type 1 MICs were detected in 62.8 percent scans and Type 2 MICs were found in 37.2 percent scans and total MICs identified on the right side $25(\mathrm{n}=9$, type 1 and $n=9$, type 2). (Table 2)Out of 43 scans, $62.8 \%$ type 1 MIC was found, and $37.2 \%$ type 2 MIC was found on the right side $25(n=18$, type 1 and $n=7$, type 2$)$ and on the left side $18(n=8$, type 1 and $n=9$, type 2$)$. A maximum of $11.5 \mathrm{~mm}$ and minimum of $6.10 \mathrm{~mm}$ with a mean value of $8.46 \mathrm{~mm}$ were reached on the inner side of the inferior cortical border of the incisive canal onto the external side of the inferior cortical border of the mandible. The average value from the inside of the mouth of the cortical edge of the incisive canal to the outer side is $7.48 \mathrm{~mm}$ and the minimum is $1.92 \mathrm{~mm}$ with a mean of $5.13 \mathrm{~mm}$. Between the inner sides of the lingual cortical border of the incisive canal to the outer edge of the lingual border, it reached a height of $5.54 \mathrm{~mm}$ and a minimum of $2.96 \mathrm{~mm}$ with a mean value of $4.19 \mathrm{~mm}$ (Table 3 ). The descriptive statistics for the relation between the incisive mandibular canal and mental foramen on type 1 and type 2 along with the five variables listed above shows (Table 4).

Table-1: Descriptive statistics for incidence of mandibular incisive canal

\begin{tabular}{|l|r|l|l|l|l|}
\hline VARIABLES & $\mathbf{N}$ & $\mathbf{M I N}(\mathbf{m m})$ & $\mathbf{M A X}(\mathbf{m m})$ & $\mathbf{M E A N}(\mathbf{m m})$ & $\mathbf{S D}(\mathbf{m m})$ \\
\hline Root tip to incisive canal & 43 & 4.35 & 9.57 & 6.67 & 1.57 \\
\hline Incisive canal to inferior cortical border of mandible & 43 & 5.10 & 11.15 & 8.46 & 1.41 \\
\hline Incisive canal to lingual buccal plate & 43 & 1.91 & 7.48 & 5.13 & 1.27 \\
\hline Incisive canal to labial buccal plate & 43 & 2.96 & 5.54 & 4.19 & 0.73 \\
\hline Diameter of incisive canal & 43 & 1.74 & 3.13 & 2.56 & 0.37 \\
\hline
\end{tabular}

N-Number of Sample, MIN- Minimum Value , MAX-Maximum Value, SD- Standard Deviation, mm-millimeter

Table-2: Initial part of mandibular incisive canal to right \& left side of mandible

\begin{tabular}{|l|l|l|l|l|l|}
\hline Type of mandibular incisive canal to mental foramen. & \multicolumn{2}{l|}{ Right Side } & \multicolumn{2}{l|}{ Left Side } & \multirow{2}{*}{ Total } \\
\cline { 2 - 5 } & $\mathrm{N}$ & $\%$ of scans & $\mathrm{N}$ & $\%$ of scans & 27(62.8\%) \\
\hline Type I & 18 & 66.7 & 9 & 33.3 & 2 \\
\hline Type II & 7 & 43.8 & 9 & 56.2 & $16(37.2 \%)$ \\
\hline Total & 25 & 41.9 & 18 & 58.1 & $43(100 \%)$ \\
\hline
\end{tabular}

N-Number of Sample

Table-3: Descriptive statistics for the whole sample

\begin{tabular}{|l|l|l|l|l|l|}
\hline VARIABLES & $\mathbf{N}$ & $\mathbf{M I N}(\mathbf{m m})$ & $\mathbf{M A X}(\mathbf{m m})$ & $\mathbf{M E A N}(\mathbf{m m})$ & SD (mm) \\
\hline Root tip to incisive canal & 60 & 4.35 & 9.57 & 6.76 & 1.57 \\
\hline $\begin{array}{l}\text { Incisive canal to inferior cortical border of } \\
\text { mandible }\end{array}$ & 60 & 6.10 & 11.15 & 8.46 & 1.41 \\
\hline Incisive canal to lingual buccal plate & 60 & 1.91 & 7.48 & 5.13 & 1.27 \\
\hline Incisive canal to labial buccal plate & 60 & 2.96 & 5.54 & 4.91 & 0.73 \\
\hline Diameter of incisive canal & 60 & 1.74 & 3.01 & 2.56 & 0.37 \\
\hline
\end{tabular}

N-Number of Sample, MIN- Minimum Value, MAX-Maximum Value, SD- Standard Deviation, mm-millimeter 
Roul A et al., Saudi J Oral Dent Res, September, 2020; 5(9): 447-451

Table-4: Descriptive statistics for relation of mandibular incisive canal to mental foramen

\begin{tabular}{|l|l|l|l|l|l|l|}
\hline \multirow{4}{*}{ TYPE I } & VARIABLES & $\mathbf{N}$ & MIN (mm) & $\begin{array}{l}\text { MAX } \\
(\mathbf{m m})\end{array}$ & $\begin{array}{l}\text { MEAN } \\
(\mathbf{m m})\end{array}$ & SD (mm) \\
\cline { 2 - 6 } & Root tip to incisive canal & 27 & 4.35 & 9.46 & 6.56 & 1.49 \\
\cline { 2 - 6 } & Incisive canal to inferior cortical border of mandible & 27 & 6.79 & 11.15 & 8.53 & 1.36 \\
\cline { 2 - 6 } & Incisive canal to lingual buccal plate & 27 & 1.91 & 6.96 & 4.95 & 1.13 \\
\cline { 2 - 6 } & Incisive canal to labial buccal plate & 27 & 3.15 & 5.54 & 4.37 & 0.74 \\
\cline { 2 - 6 } & Diameter of incisive canal & 27 & 1.74 & 3.13 & 2.60 & 0.34 \\
\hline \multirow{5}{*}{ TYPE II } & Root tip to incisive canal & 16 & 4.69 & 9.57 & 7.09 & 1.69 \\
\cline { 2 - 6 } & Incisive canal to inferior cortical border of mandible & 16 & 6.10 & 11.13 & 8.33 & 1.52 \\
\cline { 2 - 6 } & Incisive canal to lingual buccal plate & 16 & 3.14 & 7.45 & 5.44 & 1.48 \\
\cline { 2 - 6 } & Incisive canal to labial buccal plate & 16 & 2.96 & 5.40 & 3.83 & 0.64 \\
\cline { 2 - 6 } & Diameter of incisive canal & 16 & 1.74 & 3.13 & 2.50 & 0.42 \\
\hline
\end{tabular}

N-Number of Sample, MIN- Minimum Value, MAX-Maximum Value, SD- Standard Deviation, mm-millimeter

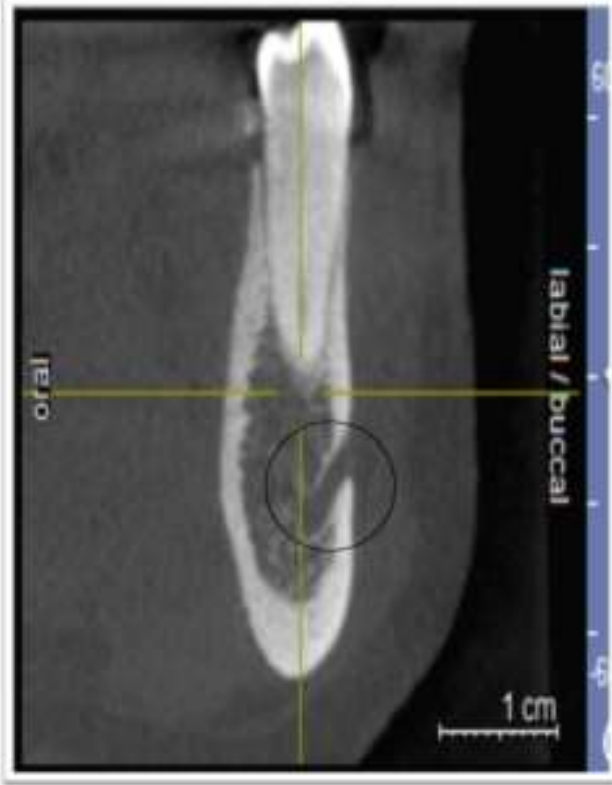

Fig-1A: .MIC starting before the opening of the MF

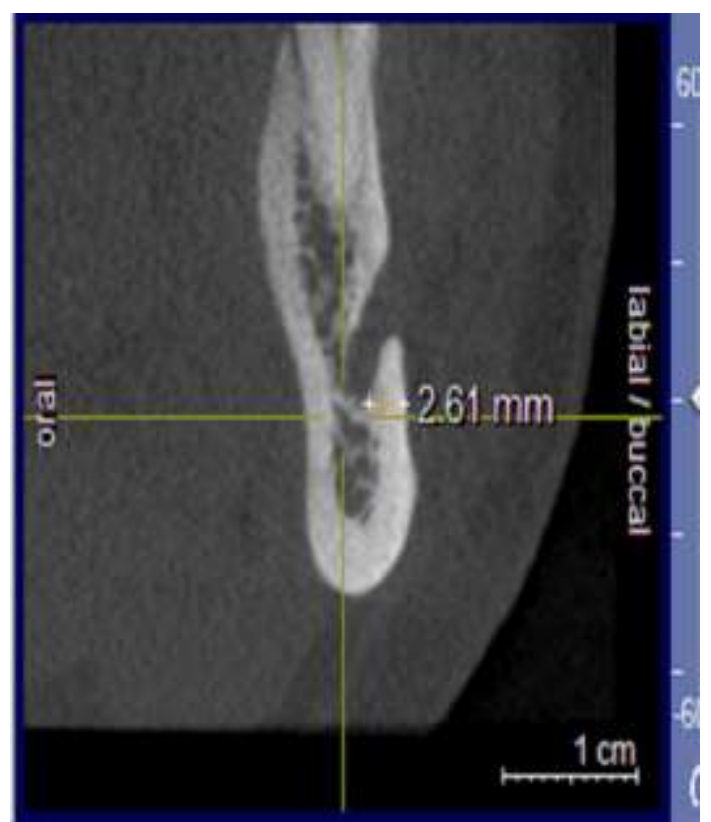

Fig-2A: The inner side of the mandibular incisive canal to the labial buccal plate

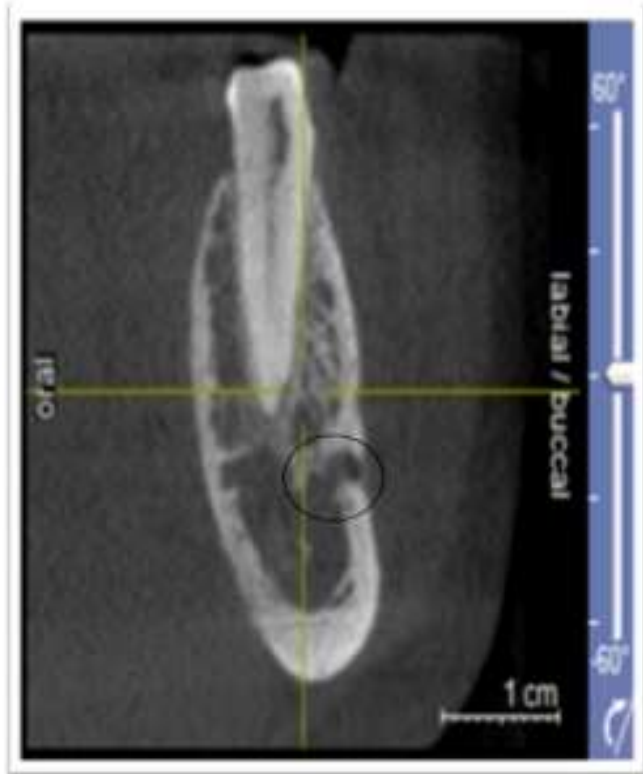

Fig-1B: .MIC starting at the level of the MF

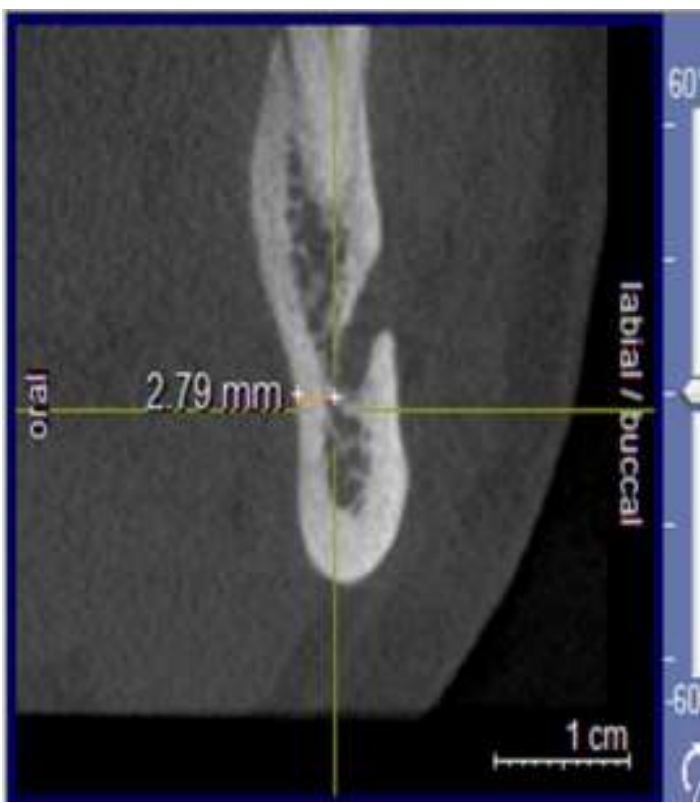

Fig-2B: The inner side of the mandibular incisive canal to the lingual buccal plate. 


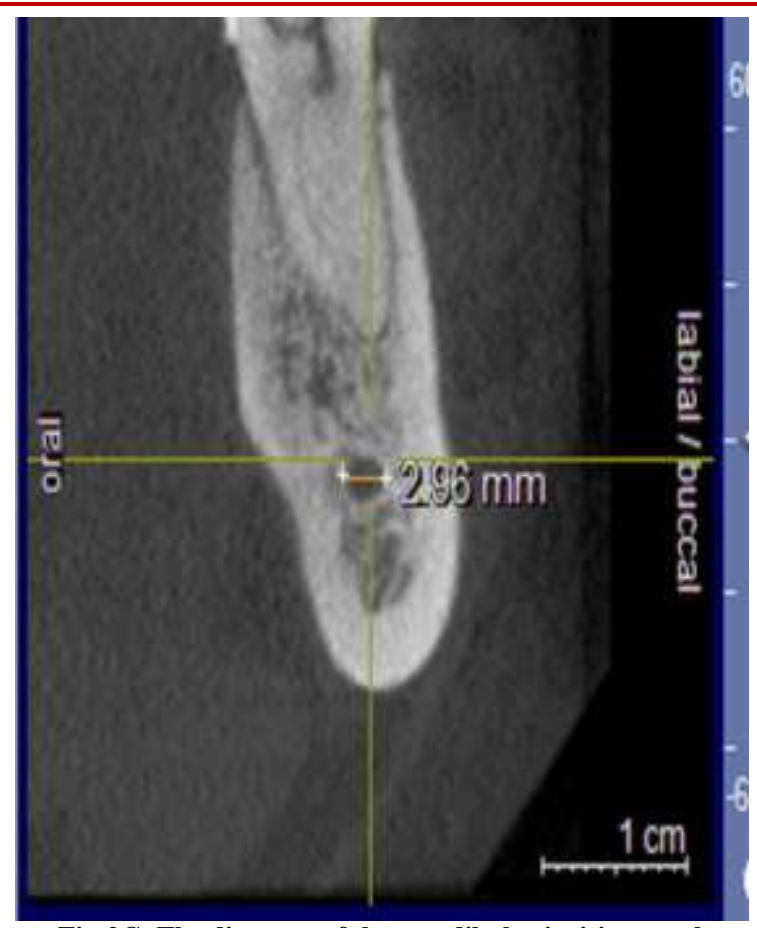

Fig-2C: The diameter of the mandibular incisive canal

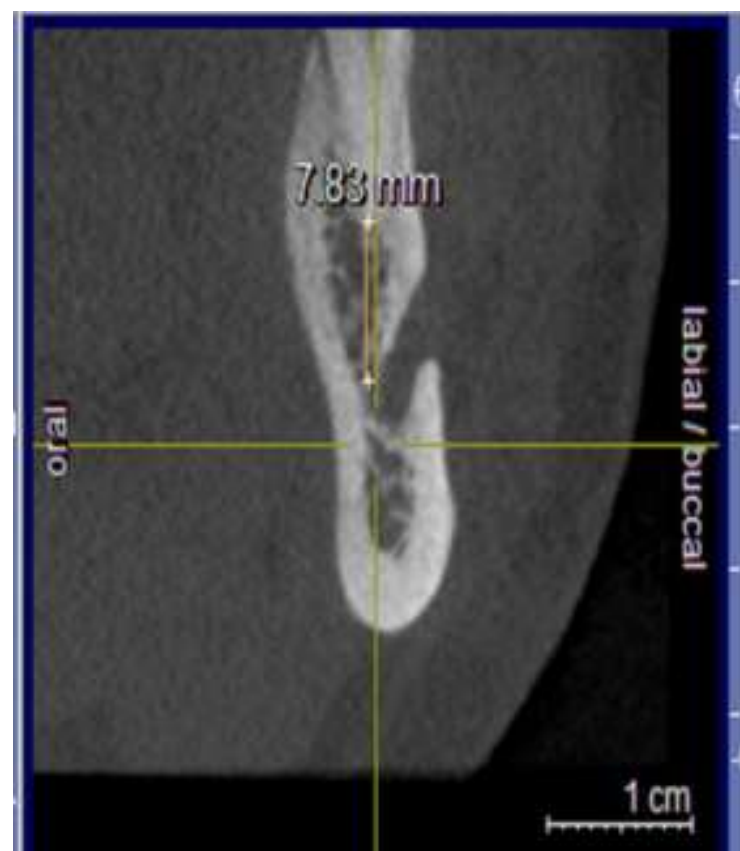

Fig-2D: Upper cortical border of mandibular incisive canal to root tip

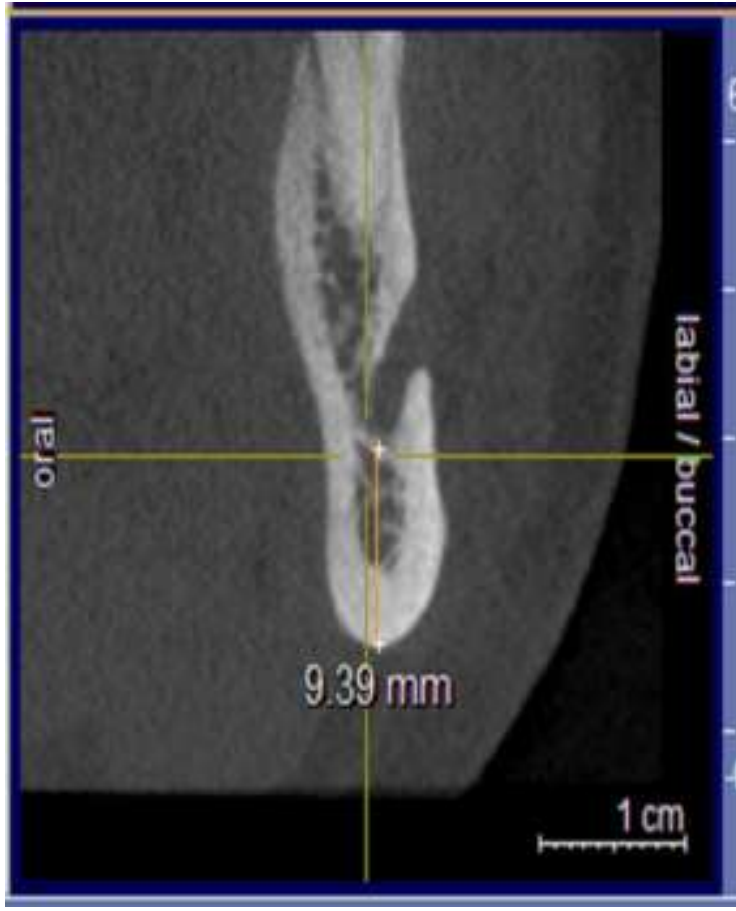

Fig-2E: Lower cortical border of mandibular incisive canal to inferior cortical border of the mandible

\section{DISCUSSION}

In this analysis, the incidence of mandibular incisive canal was 71.67 per cent, i.e. 43 scans showed the presence of mandibular incisive canal out of 60 scans, while Malusareet al. [6] 87\%, Ramesh et al. [10] 76.66\% and Pires CA et al. [11] 83\%. The MIC-MF relation in Type 1 is $45 \%$ (27 out of 60 scans) and Type 2 is $26.67 \%$ (16 out of 60 scans) with a men MIC diameter of $2.56 \mathrm{~mm}$ is shown in this study, and similar Ramesh et al. [11] study shown that in MIC-MF relationship, MF from the MIC level starting at $48.3 \%$ and MIC from the MF level at 28.3\%. In 2013, Yovchevet al. [9] studied 140 CBCT scans and found that $86.4 \%$ of MICs started before the opening of the MF (type1) and $13.7 \%$ at MF level (type 2), with a mean MIC diameter of $2.52 \mathrm{~mm}$ close to the vestibular surface. In their study, Malusareet al. [6] concluded that $45.8 \%$ and $54.2 \%$ were found in type 1 and type 2 respectively with a mean difference of MIC $3.1 \mathrm{~mm}$, which is comparatively higher than in our current study. In addition, Santos et al.[12] recently assessed the reliability and reproducibility of measurements with CBCT and demonstrated good agreement between the examiners. The occurrence of MIC could not be detected in this study of 17 scans. Specific sensitivity and thicknesses of slices or different sizes of voxels have been observed.Various studies have shown that MIC grows smaller with progression towards mental foramen which decreases in size and sometimes loses morphology of the incisive nerve as a true neural vascular club near the midline of the neurovascular plexus that reduces its diameter, so MIC can or cannot be conceived of in CBCT $[6,8,13,14]$.In type 2 MIC cases, it has been reported that the lingual location of 
the implant protects the neurovascular bundle in the canal, enhances osteointegration and eventually avoids neurosensory disturbances [6]. A variety of studies have been performed with regard to the size of the incisive canal and the thickness of the surrounding bone, and in the research of Huang et al. [15] it has been shown that the incisive canal with a larger diameter may result in osseointegration of the implants due to a decrease in bone-implant contact, and Rosenquist [16] did a study in which it was shown that the implant could also not be integrated with the gap.Based on the findings of the anatomical analysis, it can be reported that a welldefined incisive canal appears as an intraosseous extension of the lower alveolar canal.

\section{CLINICAL SIGNIFICANCE}

The clinical significance of this study is mapping of the MIC with adjacent anatomical structures in order to avoid pre-surgical, surgical and post-surgical complications and potential injury to the incisive canal. In order to do this, a comprehensive and detailed assessment with close observation by the operator is necessary and a case by case investigation should be carried out with the aid of CBCT.

\section{LIMITATIONS}

The minimum research sample was selected randomly and was carried out in the Chhattisgarh population. Since this is a pilot study, another factor, such as the gender of the population, has yet to be determined, although some differences in the location of the anatomical structures have been identified. This research can be carried out in any part of the planet with any other community.

\section{REFERENCES}

1. Mraiwa, N., Jacobs, R., Moerman, P., Lambrichts, I., van, Steenberghe, D., Quirynen, M. (2003). Presence and course of the incisive canal in the human mandibular interforaminal region: twodimensional imaging versus anatomical observations. SurgRadiolAnat, 25: 416-423.

2. Almasri, M., El-Hakim, M. (2012). Fracture of the anterior segment of the atrophic mandible related to dental implants. Int J Oral MaxillofacSurg, 41: 646-9.

3. Raitz, R., Shimura, E., Chilvarquer, I., Pereira, M.F. (2014). Assessment of the Mandibular Incisive Canal by Panoramic Radiograph and Cone-Beam Computed Tomograph. International Journal of Dentistry. http://dx.doi.org/10.1155/2014/187085

4. Apostolakis, D., Brown, J. (2013). The dimensions of the mandibular incisive canal and its spatial relationship to various anatomical landmarks of the mandible: A study using cone-beam computed tomography. Int J Oral Maxillofac Implants, 28: $117-2$
5. Topçu, A.O., Avcu, N., Uysal, S., Yamalik, N. (2015). Presence, Location and Course of Mandibular Incisive Canal and Inter-Examiner Variation: A Spiral CT Scan Study Clinical Dentistry and Research, 39(2): 56-68

6. Malusare, P.C., Navalkar, A., Das, D., Patil, B. (2019). Assessing the dimensions of the mandibular incisive canal and its relationship to adjacent anatomical landmarks using cone-beam computed tomography in Indian sub-population A retrospective study. J Indian Acad Oral Med Radiol, 31: 100-6.

7. Topçu, A., Avcu, N., Uysal, S., Yamalı, N. (2015). Presence, location and course of mandibular incisive canal and inter-examiner variation: A spiral CT scan study. Clin Dent Res, 39, 56-8.

8. Jacobs, R., Mraiwa, N., Van, Steenberghe, D., Sanderink, G., Quirynen, M. (2004). Appearance of the mandibular incisive canal on panoramic radiographs. SurgRadiolAnat, 26: 329-333.

9. Yovchev, D., Deliverska, E., Indjova, J., Zhelyazkova, M. (2013). Mandibular incisive canal: A cone-beam computed tomography study. BiotechnolBiotechnol Equip, 27: 3848-51.

10. Ramesh, A., Rijesh, K., Sharma, A., Prakash, R., Kumar, A., Karthik. (2015). The prevalence of mandibular incisive nerve canal and to evaluate its average location and dimension in the Indian population. J Pharm BioalliedSci, 7(Suppl 2): S594-6.

11. Pires, C.A., Bissada, N.F., Becker, J.J., Kanawati, A., Landers, M.A. (2012). Mandibular incisive canal: Cone-beam computed tomography. Clin Implant Dent Relat Res, 14: 67-73.

12. Santos, T., Gomes, A.A., Melo, D.G., Melo, A.R., Cavalcante, J.R., Araújo, L.G. (2012). Evaluation of reliability and reproducibility of linear measurements of cone-beam computed tomography. Indian J Dent Res, 23: 473-8.

13. Uchida, Y., Yamashita, Y., Goto, M., Hanihara, T. (2007). Measurement of anterior loop length for the mandibular canal and diameter of the mandibular incisive canal to avoid nerve damage when installing endosseous implants in the interforaminal region. J Oral MaxillofacSurg, 65: 1772-9.

14. Parnia, F., Moslehifard, E., Hafezeqoran, A., Mahboub, F., Mojaver-Kahnamoui, H. (2012). Characteristics of anatomical landmarks in the mandibular interforaminal region: A cone-beam computed tomography study. Med Oral Patol Oral Cir Bucal, 17: 420-5.

15. Huang, H., Liu, P., Li, X., Pei, Z., Yang, X., Bai, S. (2013). Mandibular incisive canal by cone beam CT. Hua Xi Kou Qiang Yi XueZaZhi, 31: 479-82.

16. Rosenquist, B. (1996). Is there an anterior loop of the inferior alveolar nerve? Int $J$ Periodontics Restorative Dent, 16: 40-5. 